\title{
The control of the specificity of CD4 T cell responses: thresholds, breakpoints, and ceilings
}

\section{Andrea J. Sant *, Francisco A. Chaves, Scott A. Leddon and Jacqueline Tung}

Department of Microbiology and Immunology, David H. Smith Center for Vaccine Biology and Immunology, University of Rochester Medical Center, Rochester, NY, USA

\section{Edited by:}

Laura Santambrogio, Albert Einstein College of Medicine, USA

\section{Reviewed by:}

Lawrence J. Stern, University of Massachusetts Medical School, USA Jacques Thibodeau, Université de Montréal, Canada

\section{*Correspondence:}

Andrea J. Sant, Department of Microbiology and Immunology, David H. Smith Center for Vaccine Biology and Immunology, University of Rochester Medical Center, 601 Elmwood Avenue, Box 609, Rochester, NY 14642, USA e-mail: andrea_sant@urmc.rochester edu
It has been known for over 25 years that CD4 $\mathrm{T}$ cell responses are restricted to a finite number of peptide epitopes within pathogens or protein vaccines. These selected peptide epitopes are termed "immunodominant." Other peptides within the antigen that can bind to host MHC molecules and recruit CD4 T cells as single peptides are termed "cryptic" because they fail to induce responses when expressed in complex proteins or when in competition with other peptides during the immune response. In the last decade, our laboratory has evaluated the mechanisms that underlie the preferential specificity of CD4T cells and have discovered that both intracellular events within antigen presenting cells, particular selective DM editing, and intercellular regulatory pathways, involving IFN- $\gamma$, indoleamine 2,3-dioxygenase, and regulatory $T$ cells, play a role in selecting the final peptide specificity of CD4 T cells. In this review, we summarize our findings, discuss the implications of this work on responses to pathogens and vaccines and speculate on the logic of these regulatory events.

Keywords: MHC, CD4T cells, immunodominance, immunoregulation, HLA-DM

\section{CD4 T CELL IMMUNODOMINANCE TO FOREIGN ANTIGENS} AND PATHOGENS IS PEPTIDE INTRINSIC AND DETERMINED BY THE KINETIC STABILITY OF PEPTIDE: CLASS II

\section{COMPLEXES}

There has been tremendous interest in understanding the "rules" of peptide selection by MHC class II molecules and the resulting elicitation of $\mathrm{CD} 4 \mathrm{~T}$ cells during the immune response to pathogens or protein vaccines. Many early models supported the importance of proteolytic processing $(1,2)$ and structural constraints of the peptide within the protein $(3,4)$ as primary features that determined a peptide's ability to recruit CD4 T cells. Collectively, these studies suggested that the efficiency of proteolytic release of the peptide was a key determinant of its ultimate immunodominance. However, systematic studies by our laboratory, summarized in Figure 1, on foreign proteins have revealed that the immunodominance of a class II: peptide is due to its intrinsic features, characterized by its spontaneous kinetic stability (5-8). Peptides that successfully recruit CD4 $\mathrm{T}$ cells from the endogenous polyclonal $\mathrm{T}$ cell repertoire display very slow off-rates $\left(t_{1 / 2}>75 \mathrm{~h}\right.$ at $\left.\mathrm{pH} 5.3\right)$. In contrast, peptides that fail to recruit $\mathrm{CD} 4 \mathrm{~T}$ cells dissociate very rapidly from class II molecules $\left(t_{1 / 2}<10 \mathrm{~h}\right)$. Immunodominance can be manipulated by amino acid changes at sites that anchor the peptide to MHC class II, while leaving T cell receptor (TcR) contact residues within the peptide unperturbed. This latter point is critical, in that with $\mathrm{T}$ cell precursor frequency held constant, the kinetic stability of class II peptide complexes behaves as a "rheostat," up- and down-regulating a peptide's ability to recruit CD4 $\mathrm{T}$ cells. Finally, the finding that a peptide can be moved into a different protein structure, or in different sites on a given protein and maintain its immunodominant or cryptic character (9) has indicated that the property of immunodominance is independent of protein context. This conclusion has important implications for vaccine strategies that seek to incorporate peptides into multiepitope vaccines [reviewed in Ref. $(10,11)]$ and suggests that such approaches will allow a peptide to successfully recruit CD4 T cells independently of the context into which it is incorporated and its neighboring peptides.

\section{THE ROLE OF DM EDITING IN SELECTING IMMUNODOMINANT EPITOPES IN RESPONSE TO PROTEIN VACCINATION}

The MHC-linked DM protein was first discovered because of its role in endosomal release of an invariant chain (Ii) degradation product, a small peptide termed CLIP (Class II invariant chain-derived peptide), that occupies the class II binding pocket immediately after the synthesis of class II and Ii glycoproteins in the endoplasmic reticulum (12). For many allelic forms of class II, this release of CLIP is a requisite event in intracellular peptide loading (13-18). We and others (19-24) showed that DM also has an editing function for removal of endogenous self-peptides from the class II binding pocket, thus shaping the repertoire of "self" recognized by the immune system. Our laboratory showed that for foreign exogenous antigens, DM editing within APC plays a key role in determining immunodominance $(5,7,19)$. Highly stable peptide: class II complexes are resistant to DM editing and emerge at the cell surface of APC with high density, while those peptides that bound to MHC class II molecules with low stability are removed by DM during endosomal processing $(5-7,9)$. These latter types of peptides, cryptic epitopes, thus fail to reach the cell surface at sufficient density to recruit CD4 T cells. The conclusion regarding selective DM editing by our laboratory from in vivo and in vitro studies and by others [reviewed in Ref. $(7,25-30)$ ] is 


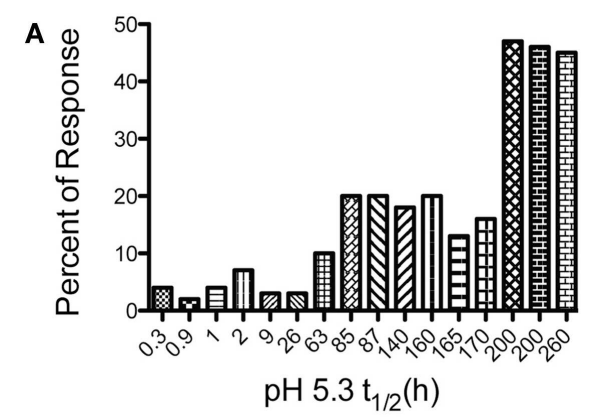

FIGURE 1 | The kinetic stability of peptide-MHC class II complexes is a key biochemical parameter that dictates CD4T cell immunodominance. Test peptide sequences with a range of kinetic stabilities were engrafted into the MalE protein of E. coli and used to immunize mice. At the peak of the immune response, CD4 T cells specific for the test peptide or the endogenous MalE epitopes were quantified with IL-2 peptide-specific EliSpot assays. The percent of the total antigen-specific CD4T cells specific for the test peptides are compared to the spontaneous dissociation rate of

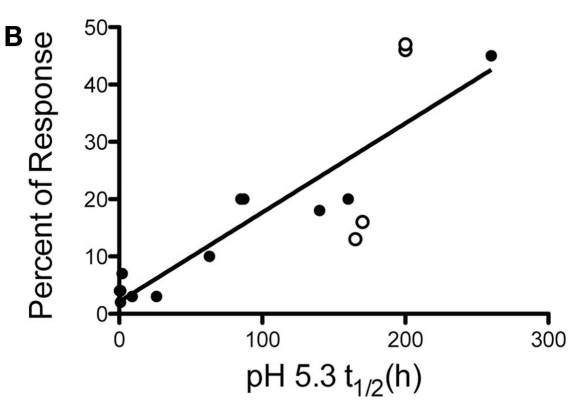

peptide-MHC class II complexes at pH 5.3. (A) To visualize breakpoints in immunodominance (e.g., cryptic, subdominant, dominant) the magnitude of the peptide-specific response of different peptides are presented in order the increasing kinetic stability of the $1-A^{d}$ peptide complex. (B) A near linear relationship is found when between kinetic stability and CD4 T cell immunodominance when values in $(\mathbf{A})$ are represented on a linear scale. Filled symbols $R^{2}=0.91$, with all symbols $R^{2}=0.75$. Data shown are adapted from previous published studies $(5,8,9,36)$. supported by biochemical and structural studies $(31-35,38)$ that show that interactions that anchor peptides to class II molecules, particularly at the peptides's amino terminus, can render these high stability peptide: class II complexes relatively resistant to DM binding and editing.

\section{BREAKPOINTS AND CEILINGS OF IMMUNODOMINANCE}

The direct relationship observed between the kinetic stability of peptide: MHC class II complexes has raised the question of the threshold or breakpoint of immunodominance. If kinetic stability of peptide: class II complexes plays a deterministic role in elicitation of CD4 T cell responses, one can ask, "what is the kinetic stability breakpoint at which it can be certain that a peptide will successfully elicit an immune response?" We have examined this issue most extensively for the murine $\mathrm{I}-\mathrm{A}^{\mathrm{d}}$ molecule in response to intact foreign antigens. Figure 1 indicates the peptide's offrate from $\mathrm{I}-\mathrm{A}^{\mathrm{d}}$ at endosomal $\mathrm{pH}$ and relative immunodominance when incorporated into the heterologous protein, MalE, the maltose binding protein of E. coli $(9,37)$. This comparison allows internal control for competing peptides within the antigen. From these data (Figure 1A), one can conclude that the breakpoint that allows a cryptic peptide to elicit a readily measurable fraction of the response (e.g., at least $10 \%$ of the total response) will have an off-rate $\left(t_{1 / 2}\right)$ with I-A ${ }^{\mathrm{d}}$ in the range of $60-80 \mathrm{~h}$. We have not observed any epitope that fails to recruit CD4 T cells that has a half-life with I-A ${ }^{\mathrm{d}}>70 \mathrm{~h}$. Similarly, we have not observed any peptide that successfully recruits $\mathrm{CD} 4 \mathrm{~T}$ cells that has dissociation half time from I-A ${ }^{\mathrm{d}}$ that is $<10 \mathrm{~h}$.

In predictions of immunodominance, one issue that is unresolved is what features of the epitope dictates the maximal abundance of CD4 T cells or "ceiling" of the response that any given epitope can achieve. Our studies have revealed that although the requirements for emergence of a peptide into immunodominance are fairly predictable, some peptides show anomalies in the maximal number of CD4 T cells that they recruit, when frequencies are measured at the peak of the response in the local draining lymph node. This phenomenon of variable ceilings is illustrated in Figure 1B, where different antigenic peptides are compared for their ability to recruit CD4 T cells when in MalE. Although there is a linear relationship and positive correlation (filled symbols $R^{2}=0.91$ ), between kinetic stability of class II: peptide complexes with immunodominance, some peptides (open symbols) deviate from this relationship. The peptides with somewhat anomalous behavior include Leishmania LACK [161-173] and MalE [69-84], that recruit a larger fraction of the response than predicted from their off-rates from I-A ${ }^{\mathrm{d}}$, and others, such as HA [126-138 T > M] that recruit fewer than the expected number of CD4 T cells. We do not yet understand what underlies these differences in maximal response, but can imagine two distinct possibilities. The first is that the DM sensitivity of a given peptide: MHC complex within the priming APC deviates from its spontaneous off-rate, perhaps as a function of the strength of the $\mathrm{P} 1$ pocket interaction or the conformation of the complex around this region. For highly DMresistant peptides, the true initial epitope density displayed by the priming dendritic cells (DC) may thus be increased relative to others with similar spontaneous off-rates from class II. Others may be particularly DM-sensitive and have lower initial epitope density than predicted by their dissociation rate. In agreement with this possibility are the findings of Stern and colleagues (30) who found that DM susceptibility of class II complexes correlates strongly with $\mathrm{CD} 4 \mathrm{~T}$ cell recognition and the findings of Mellins and coworkers whose studies revealed disparities between susceptibility to DM editing and the intrinsic off-rates of class II: peptide complexes (38). The second possibility to explain variable ceilings relative to off-rates is that different peptides have TcR contact residues that recruit variable numbers of T cell precursors from the naïve repertoire. The techniques for measuring naïve CD4 T cell precursors specific for single peptide: MHC class II molecules using tetramer-based technology allowed an estimation of number of $\mathrm{T}$ cells that recognize individual complexes. These types of empirical approaches (39-41), as well as other theoretical approaches (42) suggest that there can be a significant range in 
the number of $\mathrm{T}$ cells that can respond to different peptide: class II complexes. Such variability has generally been ascribed to negative selection during intrathymic development. It is possible that the final magnitude or ceiling of the response to peptides in the local draining lymph nodes under competitive conditions may be influenced by the precursor frequency of the peptide-reactive CD4 $\mathrm{T}$ cells in the host as well as DM editing.

It is important to note that the paradigm we have established between the kinetic stability of peptide: class II complexes, DM editing, and immunogenicity of peptides is expected to hold only for pathogen-derived or foreign peptides that have little homology to "self" proteins in the host. Deletion of CD4 T cells through partial or total homology to self can dramatically re-shape the TcR repertoire, eliminating many of the potentially antigen-reactive CD4 T cells (43-46). There may also be enhanced TcR repertoire selection for some related peptides due to positive selection with peptide analogs (47). Thus, major perturbations of the T cell repertoire for epitopes closely related to "self" is likely to modulate the magnitude of the elicited response and could change classification of some peptides within the categories of immunodominant, subdominant, or cryptic epitopes. Deducing the relative role of DM editing in APC versus precursor frequency in a complex immune response requires more explicit experimentation.

\section{COMPETITIVE CD4 T CELL RESPONSES TO PEPTIDE VACCINATION}

Most of the mechanisms demonstrated or proposed to control immunodominance have centered on the role that endosomal processing and peptide loading onto class II plays in selecting the final specificity of CD4 T cells. It was thus quite surprising to discover in peptide vaccination studies that although cryptic peptides elicit robust immune responses in vivo when introduced alone, when they are co-introduced with other peptides, immunodominance hierarchies are established (48). Interestingly, and similar to what we had found for peptides within intact antigens, the immunogenicity of peptides during multi-peptide vaccination correlated with their stability with the presenting class II molecule. Low stability cryptic peptides fail to recruit cells when co-introduced with other, more dominant peptides, while high stability dominant peptides successfully recruit CD4 T cells independently of other peptides that are co-introduced into the host.

There are a number of key features we have discovered in this control CD4 T cell specificity after multi-peptide immunization $(48,49)$. First, the loss in responses requires that the competing peptides be introduced in the same site, within the same emulsion and most importantly, be presented on the same APC. Thus, the inhibition is local rather than systemic. Second, bystander dominant peptides do not inhibit the response to cryptic peptides through competition for host MHC molecules. Although intuitively appealing, two pieces of data argue this possibility. First, excess exogenously added irrelevant peptides that can bind to host MHC class II molecules do not alter the ability of the agonist cryptic peptide to elicit CD4 T cell responses. Second, dominant peptides presented by unrelated host class II molecules are able to down-regulate responses to co-introduced cryptic low stability peptides (48). Another key aspect of the inhibition is that the termination of expansion occurs midway through the response (at day 4-5). Until this point, there is no detectable influence of the bystander peptides on the response. Finally, there is no evidence that the CD4 T cells specific for dominant peptides render the APC less able to recruit CD4 T cells by "trogocytosing" [reviewed in Ref. $(50,51)]$ key co-stimulatory or adhesion molecules. Rather, all of the data accumulated thus far suggest that ongoing responses to unrelated dominant peptides down-modulate expansion of CD4 $\mathrm{T}$ cells to subdominant peptides through a network of locally active regulatory elements that involve at least IFN- $\gamma$, indoleamine 2,3-dioxygenase (IDO), and regulatory T cells (Tregs).

The components involved in the mechanisms identified are illustrated in Figure 2. All of the data accumulated to date suggested that aborted expansion of CD4 T cells specific for cryptic peptides by responses to high stability dominant peptides is caused by alterations in the local environment during early CD4 T cell expansion and differentiation. Because the expanding populations of CD4 T cells specific for dominant peptides produce IFN- $\gamma$ as their primary effector cytokine, we tested both IFN- $\gamma$-deficient mice and IFN $-\gamma$ R deficient mice and DC, respectively. Use of either genetic model led to significantly diminished negative effects of bystander dominant, CD4 T cell responses (49). IFN- $\gamma$ is known to have multiple avenues for suppressing CD4 $\mathrm{T}$ cell responses [reviewed in Ref. (52-54)]. It can directly induce proliferative arrest and apoptosis cells that bear the IFN- $\gamma$-R2 signaling component of the IFN- $\gamma$ receptor, which is selectively expressed on Th2 cells and naïve CD4 T cells. IFN- $\gamma$ can also act indirectly to down-modulate adaptive $\mathrm{T}$ cell immunity through effects on DC, promoting localized production of IDO. IDO is an immunomodulatory enzyme that has multiple effects on immune responses [reviewed in Ref. (52, 55-60)]. It catalyzes the rate-limiting step in tryptophan degradation, inducing tryptophan deprivation, which can induce the integrated stress response program in T cells (61). Tryptophan degradation also leads to production of tryptophan metabolites, such as kynurenines, that are broadly immunosuppressive. IDO-induced pathways also promote Treg through modification of DC. Several mechanisms have been proposed for the generation of FoxP3-expressing Tregs through IDO. The tryptophan metabolite 3-HAA induces the expression of TGF- $\beta$ in DC and concurrently causes the conversion of T cells into Tregs (62). Also, Treg generation can be facilitated by binding of kynurenine to the aryl hydrocarbon receptor in T cells (63). These regulatory pathways are critical in counter regulatory immunity to pathogens and in self-tolerance pathways [reviewed in Ref. (55, 64-66)]. We found that inhibition of production of IDO, use of genetic models to eliminate production of, or responsiveness to IFN- $\gamma$ and finally depletion of Treg, each help rescue suppressed responses to cryptic peptides during multi-peptide immunization. Together, our data suggest that IFN- $\gamma$, IDO, and Treg all participate in shaping the specificity of the CD4 T cells elicited during multi-peptide immunization. These regulatory events and mediators also likely participate in the normal contraction of immune responses.

\section{SUMMARY AND PERSPECTIVES}

Our studies have revealed two distinct mechanisms by which the immune system selects for CD4 T cell reactivity to peptides that persist on the MHC class II molecule, illustrated in Figure 2. Selective DM editing within DC promotes an initial high epitope 


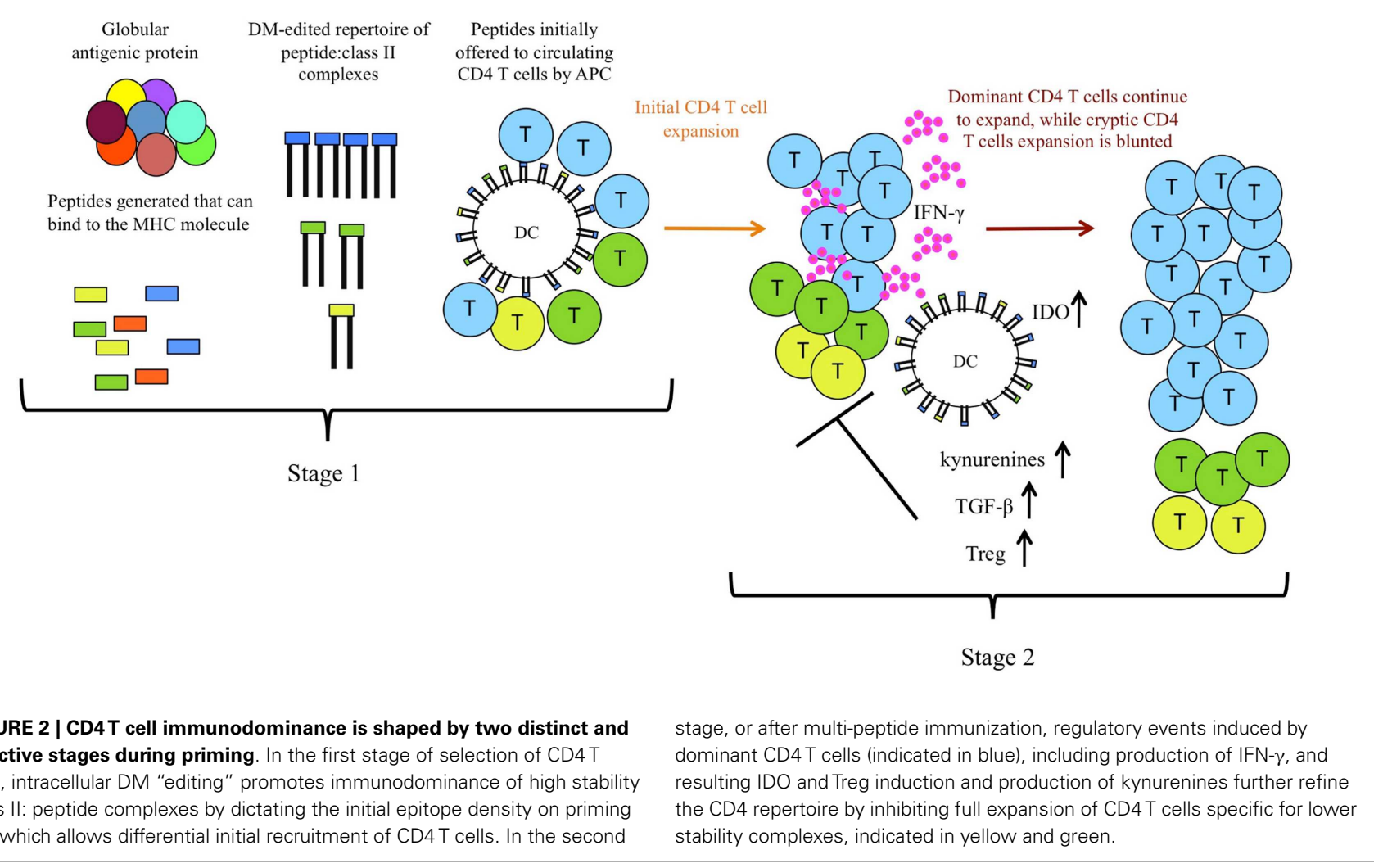

density of these peptides with class II molecules on the priming APC, while simultaneously removing peptides that cannot sustain interactions with class II. Further regulatory events during competitive responses provide a selective advantage to peptides that persist with class II molecules. The conclusion from this body of work, that there are complementary, reinforcing mechanisms to focus CD4 T cells on peptides which can bind very stably to class II molecules, suggests that persistence per se of peptide: class II complexes provide distinct advantages in the adaptive immune response.

There is accumulating evidence that CD4 and CD8 T cells differ in regard to their reliance on continued engagement of their TcR during an immune response. Unlike CD8 T cells that may need only a single encounter with APC to initiate expansion and differentiation (67), CD4 T cells or their progeny appear to require multiple contacts with antigen-bearing APC in vivo to expand and differentiate (68). For the delivery of CD4 T cell help to B cells, peptides that can persist on B cells may more effectively recruit follicular helper cells. Even beyond the acute phase of the immune response, CD4 T cells may rely on repeated TcR engagement for some functions $(69,70)$. Early work on the need for persistent antigen on immunological memory suggested that maintenance of memory CD8 T cells was independent of continued antigen and instead relied heavily on homeostatic proliferation induced by cytokines such as IL-15 [reviewed in Ref. (71)]. CD4 T cells seem to be less well sustained by cytokines alone [reviewed in Ref. (72)] and recent data suggest that low levels of peptide: class II complexes may be critical for maintenance of CD4 T cell memory (73). CD4 T cell dependence on periodic TcR engagement for expansion, differentiation, and memory may underlie the focus of the CD4 $\mathrm{T}$ cell response on peptides that bind very stably to the class II molecule. At least during the initial phase of the immune response, even if antigen is eliminated quickly, there will be sufficient complexes on APC to initiate CD4 $\mathrm{T}$ cell recognition and then sustain expansion and differentiation. Selective peptide presentation via DM editing, even in the face of diminishing antigen, will promote selective priming of CD4 $\mathrm{T}$ cells specific for these complexes, "pruning" the population of CD4 T cells specific for lower affinity ligands. Such early shaping of the CD4 $\mathrm{T}$ cell repertoire may allow the early expanding polyclonal responses to be populated by the most desirable of CD4 $\mathrm{T}$ cells, thus preventing proliferation of CD4 $\mathrm{T}$ cells that later may not be of the most utility in establishing memory or provision of $\mathrm{T}$ cell help for $\mathrm{B}$ cells. The finding that high stability class II: peptide complexes also favor a diverse CD4 TcR repertoire (74) suggests an additional advantage for these types of complexes in endowing the host with protective immunity. Combined with this early repertoire selection is a second selection event that occurs after peptides are expressed at the APC surface. Here, regulatory events further select CD4 T cells specific for complexes that persist on class II molecules through active suppression of CD4 T cells specific for less "fit" peptide: MHC complexes. These sequential, independent mechanisms likely account for the clear preference of CD4 T cells for high affinity stable peptide: class II complexes.

\section{ACKNOWLEDGMENTS}

This work was supported by grants HHSN27220201200005C, HHSN266200700008C, and R01AI51542 from the National Institutes of Health. 


\section{REFERENCES}

1. Sercarz EE, Lehmann PV, Ametani A, Benichou G, Miller A, Moudgil K. Dominance and crypticity of $\mathrm{T}$ cell antigenic determinants. Annu Rev Immunol (1993) 11:729-66. doi:10. 1146/annurev.iy.11.040193.003501

2. Moudgil KD, Sercarz EE, Grewal IS. Modulation of the immunogenicity of antigenic determinants by their flanking residues. Immunol Today (1998) 19(5):217-20. doi:10.1016/ S0167-5699(97)01233-4

3. Carmicle S, Steede NK, Landry SJ. Antigen three-dimensional structure guides the processing and presentation of helper T-cell epitopes. Mol Immunol (2007) 44(6):1159-68. doi:10.1016/j.molimm.2006.06.014

4. Dai G, Steede NK, Landry SJ. Allocation of helper T-cell epitope immunodominance according to three-dimensional structure in the human immunodeficiency virus type I envelope glycoprotein gp120. J Biol Chem (2001) 276(45):41913-20. doi:10.1074/jbc. M106018200

5. Lazarski CA, Chaves FA, Sant AJ. The impact of DM on MHC class II-restricted antigen presentation can be altered by manipulation of MHC-peptide kinetic stability. J Exp Med (2006) 203(5):1319-28. doi:10. 1084/jem.20060058

6. Weaver JM, Sant AJ. Understanding the focused CD4 T cell response to antigen and pathogenic organisms. Immunol Res (2009) 45(2-3):123-43. doi:10.1007/s12026-009-8095-8

7. Sant AJ, Chaves FA, Jenks SA, Richards KA, Menges P, Weaver JM, et al. The relationship between immunodominance, DM editing, and the kinetic stability of MHC class II: peptide complexes. Immunol Rev (2005) 207:261-78. doi:10.1111/j.0105-2896.2005. 00307.x

8. Lazarski CL, Chaves F, Jenks S, Wu S, Richards K, Weaver JM, et al. The kinetic stability of MHC class II: peptide complexes is a key parameter that dictates immunodominance. Immunity (2005) 23:29-40. doi:10.1016/j.immuni.2005.05.009

9. Weaver JM, Lazarski CA, Richards KA, Chaves FA, Jenks SA, Menges $\mathrm{PR}$, et al. Immunodominance of CD4 $\mathrm{T}$ cells to foreign antigens is peptide intrinsic and independent of molecular context: implications for vaccine design. J Immunol (2008) 181(5):3039-48.

10. Sette A, Rappuoli R. Reverse vaccinology: developing vaccines in the era of genomics. Immunity (2010) 33(4):530-41. doi:10.1016/j. immuni.2010.09.017

11. Yamada A, Sasada T, Noguchi M, Itoh K. Next-generation peptide vaccines for advanced cancer. Cancer Sci (2013) 104(1):15-21. doi:10. 1111/cas. 12050

12. Cresswell P. Assembly, transport, and function of MHC class II molecules. Annu Rev Immunol (1994) 12:259-93. doi:10.1146/annurev.iy. 12.040194.001355

13. Stebbins CC, Peterson ME, Suh WM, Sant AJ. DM-mediated release of a naturally occurring invariant chain degradation intermediate from MHC class II molecules. $J$ Immunol (1996) 157(11):4892-8.

14. Sherman MA, Weber DA, Jensen PE. DM enhances peptide binding to class II MHC by release of invariant chain-derived peptide. Immunity (1995) 3(2):197-205. doi:10. 1016/1074-7613(95)90089-6

15. Denzin LK, Robbins NF, CarboyNewcomb C, Cresswell P. Assembly and intracellular transport of HLA-DM and correction of the class II antigen-processing defect in T2 cells. Immunity (1994) 1(7):595-606. doi:10.1016/10747613(94)90049-3

16. Busch R, Mellins ED. Developing and shedding inhibitions: how MHC class II molecules reach maturity. Curr Opin Immunol (1996) 8(1):51-8. doi:10.1016/ S0952-7915(96)80105-1

17. Denzin LK, Cresswell P. HLA-DM induces CLIP dissociation from MHC class II alpha beta dimers and facilitates peptide loading. Cell (1995) 82(1):155-65. doi:10.1016/ 0092-8674(95)90061-6

18. Weber DA, Evavold BD, Jensen PE. Enhanced dissociation of HLA-DR-bound peptides in the presence of HLA-DM. Science (1996) 274:618-20. doi:10.1126/science.274.5287.618

19. Katz JF, Stebbins C, Appella E, Sant AJ. Invariant chain and DM edit self-peptide presentation by major histocompatibility complex (MHC) class II molecules. J Exp Med (1996) 184(5):1747-53. doi:10. 1084/jem.184.5.1747

20. Blum JS, Ma C, Kovats S. Antigenpresenting cells and the selection of immunodominant epitopes. Crit Rev Immunol (1997) 17(56):411-7.

21. Kropshofer H, Vogt AB, Moldenhauer G, Hammer J, Blum JS, Hammerling GJ. Editing of the HLADR-peptide repertoire by HLA-DM. EMBO J (1996) 15(22):6144-54.
22. van Ham SM, Gruneberg U, Malcherek G, Broker I, Melms A, Trowsdale J. Human histocompatibility leukocyte antigen (HLA)DM edits peptides presented by HLA-DR according to their ligand binding motifs. J Exp Med (1996) 184(5):2019-24. doi:10.1084/jem. 184.5.2019

23. Vogt AB, Arndt SO, Hammerling GJ, Kropshofer H. Quality control of MHC class II associated peptides by HLA-DM/H2-M. Semin Immuno (1999) 11(6):391-403. doi:10.1006/ smim.1999.0197

24. Nanda NK, Sant AJ. DM determines the cryptic and immunodominant fate of T cell epitopes. J Exp Med (2000) 192(6):781-8. doi:10.1084/ jem.192.6.781

25. Sadegh-Nasseri S, Chou CL, Hartman IZ, Kim A, Narayan K. How HLA-DM works: recognition of MHC II conformational heterogeneity. Front Biosci (Schol Ed) (2012) 4:1325-32. doi:10.2741/S334

26. Pos W, Sethi DK, Wucherpfennig KW. Mechanisms of peptide repertoire selection by HLA-DM. Trends Immunol (2013) 34(10):495-501. doi:10.1016/j.it.2013.06.002

27. Busch R, Rinderknecht $\mathrm{CH}$, Roh S, Lee AW, Harding JJ, Burster T, et al. Achieving stability through editing and chaperoning: regulation of MHC class II peptide binding and expression. Immunol Rev (2005) 207:242-60. doi:10.1111/j. 0105-2896.2005.00306.x

28. Schulze MS, Wucherpfennig KW. The mechanism of HLA-DM induced peptide exchange in the MHC class II antigen presentation pathway. Curr Opin Immunol (2012) 24(1):105-11. doi:10.1016/j.coi.2011.11.004

29. Karlsson L. DM and DO shape the repertoire of peptide-MHC-classII complexes. Curr Opin Immunol (2005) 17(1):65-70. doi:10.1016/j. coi.2004.11.003

30. Yin L, Calvo-Calle JM, DominguezAmorocho O, Stern LJ. HLA-DM constrains epitope selection in the human $\mathrm{CD} 4 \mathrm{~T}$ cell response to vaccinia virus by favoring the presentation of peptides with longer HLA-DM-mediated half-lives. J Immunol (2012) 189(8):3983-94. doi:10.4049/jimmunol.1200626

31. Chou CL, Sadegh-Nasseri S. HLADM recognizes the flexible conformation of major histocompatibility complex class II. J Exp Med (2000) 192(12):1697-706. doi:10. 1084/jem.192.12.1697

32. Narayan K, Chou CL, Kim A, Hartman IZ, Dalai S, Khoruzhenko S, et al. HLA-DM targets the hydrogen bond between the histidine at position beta81 and peptide to dissociate HLA-DR-peptide complexes. Nat Immunol (2007) 8(1):92-100. doi:10.1038/ni1414

33. Zarutskie JA, Busch R, Zavala-Ruiz Z, Rushe M, Mellins ED, Stern LJ. The kinetic basis of peptide exchange catalysis by HLA-DM. Proc Natl Acad Sci U S A (2001) 98(22):12450-5. doi:10.1073/pnas. 211439398

34. Pashine A, Busch R, Belmares MP, Munning JN, Doebele RC, Buckingham $\mathrm{M}$, et al. Interaction of HLADR with an acidic face of HLADM disrupts sequence-dependent interactions with peptides. Immunity (2003) 19(2):183-92. doi:10. 1016/S1074-7613(03)00200-0

35. Pos W, Sethi DK, Call MJ, Schulze MS, Anders AK, Pyrdol J, et al. Crystal structure of the HLA-DMHLA-DR1 complex defines mechanisms for rapid peptide selection. Cell (2012) 151(7):1557-68. doi:10. 1016/j.cell.2012.11.025

36. Menges PR, Jenks SA, Bikoff EK, Friedmann DR, Knowlden ZA, Sant AJ. An MHC class II restriction bias in CD4 $\mathrm{T}$ cell responses toward I-A is altered to I-E in DMdeficient mice. J Immunol (2008) 180(3):1619-33.

37. Martineau P, Guillet JG, Leclerc C, Hofnung M. Expression of heterologous peptides at two permissive sites of the MalE protein: antigenicity and immunogenicity of foreign B-cell and T-cell epitopes. Gene (1992) 118(1):151. doi:10.1016/ 0378-1119(92)90266-R [Erratum for Gene 1992 April 1; 113(1):3546;]

38. Belmares MP, Busch R, Wucherpfennig KW, McConnell HM, Mellins ED. Structural factors contributing to DM susceptibility of MHC class II/peptide complexes. J Immunol (2002) 169(9):5109-17.

39. Moon JJ, Chu HH, Pepper M, McSorley SJ, Jameson SC, Kedl RM, et al. Naive CD4(+) T cell frequency varies for different epitopes and predicts repertoire diversity and response magnitude. Immunity (2007) 27(2):203-13. doi:10.1016/j. immuni.2007.07.007

40. Chu HH, Moon JJ, Kruse AC, Pepper M, Jenkins MK. Negative selection and peptide chemistry determine the size of naive foreign peptide-MHC class IIspecific CD4+ T cell populations. J Immunol (2010) 185(8):4705-13. doi:10.4049/jimmunol.1002276 
41. Jenkins MK, Moon JJ. The role of naive $\mathrm{T}$ cell precursor frequency and recruitment in dictating immune response magnitude. J Immunol (2012) 188(9):4135-40. doi:10.4049/jimmunol.1102661

42. Kosmrlj A, Jha AK, Huseby ES, Kardar M, Chakraborty AK. How the thymus designs antigen-specific and self-tolerant $\mathrm{T}$ cell receptor sequences. Proc Natl Acad Sci U S A (2008) 105(43):16671-6. doi:10. 1073/pnas.0808081105

43. Moudgil KD. Determinant hierarchy: shaping of the self-directed $\mathrm{T}$ cell repertoire, and induction of autoimmunity. Immunol Lett (1999) 68(2-3):251-6. doi:10.1016/ S0165-2478(99)00080-2

44. Cibotti R, Kanellopoulos JM, Cabaniols JP, Halle-Panenko O, Kosmatopoulos K, Sercarz E, et al. Tolerance to a self-protein involves its immunodominant but does not involve its subdominant determinants. Proc Natl Acad Sci U S A (1992) 89(1):416-20. doi:10.1073/pnas.89.1.416

45. Moudgil KD, Southwood S, Ametani A, Kim K, Sette A, Sercarz EE. The self-directed $\mathrm{T}$ cell repertoire against mouse lysozyme reflects the influence of the hierarchy of its own determinants and can be engaged by a foreign lysozyme. J Immunol (1999) 163(8):4232-7.

46. Lo WL, Allen PM. Self-peptides in TCR repertoire selection and peripheral T cell function. Curr Top Microbiol Immunol (2013). doi:10. 1007/82_2013_319. [Epub ahead of print].

47. Hogquist KA, Jameson SC, Heath WR, Howard JL, Bevan MJ, Carbone FR. T cell receptor antagonist peptides induce positive selection. Cell (1994) 76(1):17-27. doi: 10.1016/0092-8674(94)90169-4

48. Weaver JM, Chaves FA, Sant AJ. Abortive activation of CD4 $\mathrm{T}$ cell responses during competitive priming in vivo. Proc Natl Acad Sci U S A (2009) 106(21):8647-52. doi: 10 . 1073/pnas.0811584106

49. Tung J, Sant AJ. Orchestration of CD4 $\mathrm{T}$ cell epitope preferences after multipeptide immunization. J Immunol (2013) 191(2):764-72. doi:10.4049/jimmunol.1300312

50. Ahmed KA, Munegowda MA, Xie $\mathrm{Y}$, Xiang J. Intercellular trogocytosis plays an important role in modulation of immune responses. Cell Mol Immunol (2008) 5(4):261-9. doi:10. 1038/cmi.2008.32

51. Caumartin J, Lemaoult J, Carosella ED. Intercellular exchanges of membrane patches (trogocytosis) highlight the next level of immune plasticity. Transpl Immunol (2006) 17(1):20-2. doi:10.1016/j.trim.2006.09.032

52. King NJ, Thomas SR. Molecules in focus: indoleamine 2,3dioxygenase. Int $J$ Biochem Cell Biol (2007) 39(12):2167-72. doi:10. 1016/j.biocel.2007.01.004

53. Schroder K, Hertzog PJ, Ravasi $\mathrm{T}$, Hume DA. Interferon-gamma: an overview of signals, mechanisms and functions. J Leukoc Biol (2004) 75(2):163-89. doi:10.1189/ jlb.0603252

54. Regis G, Conti L, Boselli D, Novelli F. IFNgammaR2 trafficking tunes IFNgamma-STAT1 signaling in T lymphocytes. Trends Immunol (2006) 27(2):96-101. doi:10.1016/j. it.2005.12.002

55. Fallarino F, Grohmann U. Using an ancient tool for igniting and propagating immune tolerance: IDO as an inducer and amplifier of regulatory T cell functions. Curr Med Chem (2011) 18(15):2215-21. doi: $10.2174 / 092986711795656027$

56. Mandi Y, Vecsei L. The kynurenine system and immunoregulation. J Neural Transm (2012) 119(2):197-209. doi:10.1007/s00702-011-0681-y

57. Munn DH. Indoleamine 2,3dioxygenase, tumor-induced tolerance and counter-regulation. Curr Opin Immunol (2006) 18(2):220-5. doi:10.1016/i.coi.2006.01.002

58. Mellor A. Indoleamine 2,3 dioxygenase and regulation of T cell immunity. Biochem Biophys Res Commun (2005) 338(1):20-4. doi:10.1016/j. bbrc.2005.08.232

59. Mellor AL, Munn DH. IDO expression by dendritic cells: tolerance and tryptophan catabolism. Nat Rev Immunol (2004) 4(10):762-74. doi: $10.1038 /$ nri1457

60. Fallarino F, Grohmann U, Puccetti P. Indoleamine 2,3-dioxygenase: from catalyst to signaling function. Eur J Immunol (2012) 42(8):1932-7. doi: 10.1002/eji.201242572

61. Munn DH, Sharma MD, Baban B, Harding HP, Zhang Y, Ron
$\mathrm{D}$, et al. GCN2 kinase in $\mathrm{T}$ cells mediates proliferative arrest and anergy induction in response to indoleamine 2,3-dioxygenase. Immunity (2005) 22(5):633-42. doi:10.1016/j.immuni.2005.03.013

62. Yan Y, Zhang GX, Gran B, Fallarino $\mathrm{F}, \mathrm{Yu} \mathrm{S}$, Li $\mathrm{H}$, et al. IDO upregulates regulatory $\mathrm{T}$ cells via tryptophan catabolite and suppresses encephalitogenic $\mathrm{T}$ cell responses in experimental autoimmune encephalomyelitis. JImmuno (2010) 185(10):5953-61. doi:10. 4049/jimmunol.1001628

63. Mezrich JD, Fechner JH, Zhang $\mathrm{X}$, Johnson BP, Burlingham WJ, Bradfield CA. An interaction between kynurenine and the aryl hydrocarbon receptor can generate regulatory $\mathrm{T}$ cells. J Immunol (2010) 185(6):3190-8. doi:10.4049/jimmunol.0903670

64. Harden JL, Egilmez NK. Indoleamine 2,3-dioxygenase and dendritic cell tolerogenicity. Immunol Invest (2012) 41(6-7):738-64. doi:10.3109/08820139.2012.676122

65. Gu T, Rowswell-Turner RB, Kilinc MO, Egilmez NK. Central role of IFNgamma-indoleamine 2,3-dioxygenase axis in regulation of interleukin-12-mediated antitumor immunity. Cancer Res (2010) 70(1):129-38. doi:10.1158/ 0008-5472.CAN-09-3170

66. Munn DH, Mellor AL. Indoleamine 2,3 dioxygenase and metabolic control of immune responses. Trend Immunol (2013) 34(3):137-43. doi: 10.1016/j.it.2012.10.001

67. Mercado R, Vijh S, Allen SE, Kerksiek K, Pilip IM, Pamer EG. Early programming of $\mathrm{T}$ cell populations responding to bacterial infection. $J$ Immunol (2000) 165(12):6833-9.

68. Obst R, van Santen HM, Mathis $\mathrm{D}$, Benoist C. Antigen persistence is required throughout the expansion phase of a CD4(+) T cell response. J Exp Med (2005) 201(10):1555-65. doi:10.1084/jem.20042521

69. Zaph C, Uzonna J, Beverley SM, Scott P. Central memory T cells mediate long-term immunity to Leishmania major in the absence of persistent parasites. Nat Med (2004) 10(10):1104-10. doi:10.1038/nm1108

70. Belkaid Y, Piccirillo CA, Mendez S, Shevach EM, Sacks DL.
CD4+CD25+ regulatory $\mathrm{T}$ cells control Leishmania major persistence and immunity. Nature (2002) 420(6915):502-7. doi:10.1038/nature01152

71. Surh CD, Boyman O, Purton JF, Sprent J. Homeostasis of memory $\mathrm{T}$ cells. Immunol Rev (2006) 211:154-63. doi:10.1111/j.01052896.2006.00401.x

72. van Leeuwen EM, Sprent J, Surh CD. Generation and maintenance of memory CD4(+) T Cells. Curr Opin Immunol (2009) 21(2):167-72. doi: 10.1016/j.coi.2009.02.005

73. Nelson RW, McLachlan JB, Kurtz JR, Jenkins MK. CD4+ T cell persistence and function after infection are maintained by low-level peptide: MHC class II presentation. J Immunol (2013) 190(6):2828-34. doi:10.4049/jimmunol.1202183

74. Baumgartner CK, Ferrante A, Nagaoka M, Gorski J, Malherbe LP. Peptide-MHC class II complex stability governs CD4 $\mathrm{T}$ cell clonal selection. Immunol (2010) 184(2):573-81. doi:10.4049/jimmunol.0902107

Conflict of Interest Statement: The authors declare that the research was conducted in the absence of any commercial or financial relationships that could be construed as a potential conflict of interest.

Received: 28 August 2013; accepted: 04 October 2013; published online: 23 October 2013.

Citation: Sant AJ, Chaves FA, Leddon SA and Tung J (2013) The control of the specificity of CD4 $T$ cell responses: thresholds, breakpoints, and ceilings. Front. Immunol. 4:340. doi: 10.3389/fimmu.2013.00340

This article was submitted to Antigen Presenting Cell Biology, a section of the journal Frontiers in Immunology.

Copyright (c) 2013 Sant, Chaves, Leddon and Tung. This is an open-access article distributed under the terms of the Creative Commons Attribution License (CC $B Y)$. The use, distribution or reproduction in other forums is permitted, provided the original author(s) or licensor are credited and that the original publication in this journal is cited, in accordance with accepted academic practice. No use, distribution or reproduction is permitted which does not comply with these terms. 